\title{
Emergência de plântulas e vigor de sementes de Anadenanthera colubrina (Vell.) Brenan (Fabaceae) em diferentes substratos e profundidades de semeadura
}

\author{
João Henrique Constantino Sales Silva ${ }^{1}$; Ricardo Monteiro dos Santos $^{2}$; Maria da Guia de Medeiros ${ }^{3}$; Waldilene \\ Rodrigues da Silva ${ }^{4}$; Gilvaneide Alves de Azeredo ${ }^{5}$
}

\author{
${ }^{1}$ Universidade Federal da Paraíba, ${ }^{1}$ joaohenriqueconst@gmail.com; ${ }^{2}$ ricardo.malu@ hotmail.com; \\ ${ }^{3}$ dagmedeirospb@gmail.com; ${ }^{4}$ waldilene_rodrigues@ hotmail.com $;$ azeredogil@yahoo.com.br.
}

\begin{abstract}
RESUMO: O angico (Anadenanthera colubrina (Vell.) Brenan) é uma espécie arbórea nativa pertencente a família das Fabaceae que possui importância fundamental para a fauna e flora brasileira. Para a realização de testes de emergência e/ou germinação faz-se necessário escolher um substrato adequado a fim de proporcionar elevados percentuais de germinação e bom desenvolvimento das plântulas. Assim sendo, o presente trabalho teve como objetivo avaliar o efeito de diferentes substratos e profundidades de semeadura na emergência de plântulas e no vigor de sementes de angico. Para o desenvolvimento desta pesquisa, foram escolhidos dois substratos: areia e composto orgânico; e quatro profundidades de semeadura: 0 (superfície), 1, 3 e $5 \mathrm{~cm}$. Foram avaliadas as seguintes características: emergência de plântulas (\%); índice de velocidade de emergência (IVE); tempo médio de emergência (TME) e sobrevivência (\%). O delineamento estatístico utilizado foi o inteiramente casualizado seguindo o esquema fatorial $2 \times 4$ (substratos $\times$ profundidades de semeadura), utilizando-se quatro repetições de 25 sementes por tratamento. Os dados foram submetidos à Análise de Variância, sendo aplicado o Teste de Tukey ao nível de 5\% de probabilidade com o auxílio do software ESTAT/Jaboticabal ${ }^{\circledR}$. Os resultados evidenciaram efeito significativo da interação substrato $\times$ profundidade apenas para as variáveis IVE e TME, para as demais, o efeito significativo observado foi isolado seja para a profundidade ou substrato. Considerando o efeito isolado do substrato, observou-se que o substrato composto proporcionou maiores percentagens de emergência. Quanto a profundidade, $1 \mathrm{e} 3 \mathrm{~cm}$ favoreceram a emergência de plântulas. Pode-se concluir que o substrato "composto" favoreceu a emergência e o vigor de Anadenanthera colubrina, em relação à areia. As profundidades de semeadura de 1 e $3 \mathrm{~cm}$ são as mais indicadas para testes de emergência de plântulas dessa espécie.
\end{abstract}

PALAVRAS-CHAVE: Angico; Germinação; Sementes.

\section{INTRODUÇÃO}

O angico (Anadenanthera colubrina (Vell.) Brenan) é uma espécie arbórea nativa e não endêmica do Brasil, que possui uma ampla distribuição pelo território nacional. Os frutos dessa espécie são do tipo vagem e as sementes são orbiculares e estreitamente aladas (MORIM, 2019). A espécie pode alcançar cerca de 12-15 m de altura e tronco de 30$50 \mathrm{~cm}$ de diâmetro, a sua madeira é útil para a construção civil, obras hidráulicas, confecção de dormentes, tabuado, podendo ainda ser aproveitada para arborização de parques e praças e para plantio em florestas mistas destinadas à recomposição de áreas de preservação degradadas (LORENZI, 2002).

$\mathrm{O}$ contato das sementes com o ambiente externo exerce um papel fundamental na designação de como populações e comunidades ecossistêmicas são estruturadas, sendo principalmente importante para a conservação de espécies e restauração de ecossistemas naturais (SENA et al., 2017). Ainda segundo esses autores, o entendimento da ecofisiologia da germinação, viabilidade e semeadura são necessários para compreender o estabelecimento dessa espécie, possibilitando um conhecimento mais profundo de sua aplicação na recuperação de áreas historicamente degradadas.

De acordo com Silva et al. (2007), a germinação das sementes, em função dos fatores ambientais, está associada às características ecofisiológicas das espécies. Assim, segundo esses autores, sementes de espécies pertencentes a um grupo ecológico podem necessitar de condições diferentes das de outro grupo ecológico, para expressar seu maior potencial germinativo. Dentre os fatores ambientais, o substrato e a profundidade de semeadura possuem fundamental importância no processo germinativo, pois esses fatores influenciam tanto no percentual de germinação, bem como na velocidade e uniformidade de emergência (CARVALHO; NAKAGAWA, 2012).

Em relação ao substrato, este é um dos fatores externos mais relevantes no desenvolvimento inicial das mudas em fase de viveiro, influenciando tanto a germinação das sementes quanto o crescimento das mudas, favorecendo sua produção em curto período de tempo e a baixo custo. As características físicas do substrato são extremamente relevantes, sobretudo, por ele ser usado em um estádio de desenvolvimento em que a planta é pouco tolerante ao déficit hídrico (DUTRA et al. (2012).

Além do substrato, outro fator importante a ser considerado na produção vegetal é a profundidade de semeadura, que pode influenciar o processo germinativo, sendo condicionado pela temperatura, teor de água, tipo de solo, dentre outros fatores. A semente deve ser depositada a uma profundidade adequada que permita um bom contato com o solo úmido, ocasionando elevados percentuais de emergência das plântulas (SILVA et al. 2008).

Caderno Verde de Agroecologia e Desenvolvimento Sustentável (ISSN 2358-2367) v. 9, n.7, e-7054, 2019 doi: 10.18378/cvads.v9i7.7054 
Por ser bastante utilizada na arborização urbana e na recuperação de áreas degradadas, o conhecimento acerca das condições ótimas para germinação dessa espécie se faz necessário e imprescindível. Nesse sentido, a presente pesquisa teve como objetivo avaliar o efeito de diferentes substratos e profundidades de semeadura na emergência e vigor de sementes de Anadenanthera colubrina (Vell.) Brenan.

\section{MATERIAL E MÉTODOS}

A pesquisa foi realizada no Viveiro de Produção de Mudas pertencente ao Setor de Agricultura do Centro de Ciências Humanas Sociais e Agrárias da Universidade Federal da Paraíba, Campus III, no município de Bananeiras/PB, cidade situada na microrregião do brejo paraibano, onde a altitude local varia de 510 à $617 \mathrm{~m}$, situando-se entre as coordenadas geográficas $6^{\circ} 41^{\prime} 11^{\prime}$ ' de latitude sul e $35^{\circ} 37^{\prime} 41^{\prime \prime}$ de longitude, a oeste de Greenwich, com clima quente e úmido. A temperatura da região varia entre a máxima de $38^{\circ} \mathrm{C}$ e a mínima de $18^{\circ} \mathrm{C}$ com a precipitação média anual de $1.200 \mathrm{~mm}$ (IBGE, 2012).

As sementes foram provenientes de frutos maduros coletados em matrizes no remanescente florestal de Brejo de Altitude pertencente ao Campus III/UFPB. O beneficiamento dos frutos e sementes ocorreu no Laboratório de Tecnologia de Sementes do CCHSA/UFPB. Para a condução do experimento, foram escolhidos dois substratos, sendo eles: a) areia lavada com granulometria média e b) composto orgânico oriundo de compostagem; e quatro profundidades de semeadura: 0 (superfície), 1,3 e $5 \mathrm{~cm}$. As sementes foram postas para germinar em bandejas com dimensões de 43,5 cm (comprimento) x 29,6 cm (largura) x 7,5 cm (altura), utilizando-se quatro repetições de 25 sementes, totalizando 100 sementes por tratamento.

Foram avaliadas as seguintes características: emergência de plântulas (E); índice de velocidade de emergência (IVE); tempo médio de emergência (TME); e porcentagem de sobrevivência (S). As leituras foram feitas diariamente, assim que foi observado o início da emergência (surgimento do hipocótilo) sobre os substratos, estendendo-se por um período de 16 dias após a semeadura, quando ocorreu a estabilização. O delineamento estatístico utilizado foi o inteiramente casualizado seguindo o esquema fatorial $2 \times 4$ (substratos $\times$ profundidades de semeadura), sendo aplicado o Teste de Tukey ao nível de $5 \%$ de probabilidade com o auxílio do software ESTAT/Jaboticabal ${ }^{\circledR}$.

\section{RESULTADOS E DISCUSSÃO}

De acordo com a análise de variância (Tabela 1), não houve efeito significativo para a interação substrato $\times$ profundidade nas variáveis de porcentagem de emergência e porcentagem de sobrevivência, bem como não houve efeito significativo para o fator isolado, substrato, nas variáveis TME e sobrevivência (\%). No entanto, houve efeito significativo da interação substrato $\times$ profundidade apenas para as variáveis IVE e TME, para as demais, o efeito significativo observado foi isolado para substrato nas variáveis: porcentagem de emergência e IVE. Enquanto que para o fator isolado profundidade, houve significância para todas as variáveis.

Tabela 1. Análise de variância para porcentagem de emergência (E), índice de velocidade de emergência (IVE), tempo médio de emergência (TME) e porcentagem de sobrevivência (S) de plântulas de Anadenanthera colubrina

\begin{tabular}{|c|c|c|c|c|}
\hline \multirow{2}{*}{ Fontes de variação } & \multicolumn{4}{|c|}{ Quadrados Médios } \\
\hline & E & IVE & TME & $\mathrm{S}$ \\
\hline Substrato & $420.5000^{*}$ & $25.7403 * *$ & $5.2813^{\mathrm{ns}}$ & $136.1250^{\mathrm{ns}}$ \\
\hline Profundidade & $2491.1250 * *$ & $19.6061 * *$ & $24.3017 * *$ & $2215.5833 * *$ \\
\hline Substrato $\times$ Profundidade & $118.8333^{\mathrm{ns}}$ & $3.4828 * *$ & $7.8912 * *$ & $41.5417^{\mathrm{ns}}$ \\
\hline Resíduo & 77.8958 & 0.2574 & 1.2858 & 40.1042 \\
\hline Média & 47.4 & 2.9 & 6.3 & 41.0 \\
\hline $\mathrm{CV} \%=$ & 18.6 & 17.3 & 17.7 & 15.4 \\
\hline
\end{tabular}

Na Tabela 2, são apresentados os valores médios de emergência para ambos os substratos, visto que não houve efeito significativo da interação para esta variável. O substrato oriundo da compostagem apresentou um percentual de emergência em torno de $51 \%$, diferindo estatisticamente da areia (43\%). De acordo com Araújo e Sobrinho (2011), os substratos apresentam capacidade de retenção de água dentro de uma faixa adequada para a emergência das plântulas, contribuindo para uma maior uniformidade na disponibilidade de água para as sementes. 
SILVA, J. H. C. S. et al. Emergência de plântulas e vigor de sementes de Anadenanthera colubrina (Vell.) Brenan (Fabaceae) em diferentes substratos e profundidades de semeadura. In: II Congresso Paraibano de Agroecologia \& IV Exposição Tecnológica, 2019. Anais... Caderno Verde de Agroecologia e Desenvolvimento Sustentável, Pombal, v. 9, n.7, e-7054, 2019.

Tabela 2. Efeito do substrato sobre o percentual de emergência de plântulas de Anadenanthera colubrina

\begin{tabular}{ll}
\hline Substrato & Médias \\
\hline Composto & $51 \mathrm{a}$ \\
Areia & $43 \mathrm{~b}$ \\
\hline $\mathrm{CV}=18,6 \%$ & \\
\hline \multicolumn{2}{l}{ Médias seguidas pela mesma letra na coluna não diferem significativamente entre si pelo teste de Tukey a $5 \%$ de probabilidade. }
\end{tabular}

Esses resultados sugerem que esta espécie é possivelmente responsiva à adição de nutrientes no substrato. De acordo com Oliveira e Jardim (2019), este efeito pode estar relacionado com a peculiaridade da espécie para com o substrato, sugerindo que as sementes podem exigir diferentes características físicas e químicas para atingir satisfatórios índices de germinação. Ainda conforme esses autores, o entendimento acerca das características do substrato, associado às exigências das espécies, condicionará, certamente, o sucesso no processo de emergência e crescimento da planta.

Santos (2019), estudando o efeito de substratos comerciais na produção de mudas de Caesalpinia pulcherrima (L.) Sw (Fabaceae), constatou que houve uma resposta positiva das plantas aos substratos com maior quantidade de nutrientes, e menor desenvolvimento das plantas no substrato que continha baixos níveis de nutrientes. De tal modo, Moreira et al. (2018), avaliando a produção de mudas dessa mesma espécie em substratos formulados com resíduos orgânicos, também verificaram que a elevação dos teores de macro e micronutrientes resultou em maior crescimento da planta.

Em relação ao fator isolado profundidade (Tabela 3), verificou-se que os maiores valores para a emergência foram observados nas profundidades de 1 e $3 \mathrm{~cm}$ abaixo do solo, com cerca de 57 e $64 \%$ de sementes germinadas, diferindo estatisticamente das demais profundidades. No entanto, faz-se válido destacar que na superfície (profundidade zero), o percentual de germinação foi de $42 \%$, enquanto que a $5 \mathrm{~cm}$, este percentual foi bem inferior (24\%).

Tabela 3. Efeito da profundidade de semeadura sobre o percentual de emergência de plântulas de Anadenanthera colubrina

\begin{tabular}{ll}
\hline Profundidade $(\mathrm{cm})$ & Médias \\
\hline 0 & $42 \mathrm{~b}$ \\
1 & $57 \mathrm{a}$ \\
3 & $64 \mathrm{a}$ \\
5 & $24 \mathrm{c}$ \\
\hline
\end{tabular}

$\mathrm{CV}=18,6 \%$

Médias seguidas pela mesma letra na coluna não diferem significativamente entre si pelo teste de Tukey a $1 \%$ de probabilidade.

Quanto ao índice de velocidade de emergência (IVE), houve efeito significativo $(\mathrm{p} \leq 0.01)$ para a interação substrato $\times$ profundidade de semeadura (Tabela 4). Em relação ao substrato oriundo da compostagem, nota-se que o maior valor para IVE foi obtido na superfície (profundidade zero), em torno de 5,7, diferindo estatisticamente dos demais. Enquanto que no substrato areia, o maior valor para esta variável foi observado na profundidade de $1 \mathrm{~cm}(3,4)$. Importante destacar que os menores valores de IVE foram encontrados na profundidade de $5 \mathrm{~cm}$, independentemente do substrato testado.

Esse resultado pode ser explicado pela maior camada de substrato que as sementes tiveram que romper nesta profundidade, o que fez com que emergissem de maneira mais lenta. Segundo Alves et al (2014), as profundidades menores favorecem a maior velocidade de emergência, pois oferecem menor barreira física, proporcionando o desenvolvimento das plântulas. Já nas profundidades maiores, durante o processo germinativo pode ter ocorrido maior consumo de energia, que resultou na emergência mais lenta dos demais tratamentos (ALVES et al., 2013)

Tabela 4. Efeito da interação substrato $\times$ profundidade de semeadura sobre o índice de velocidade de emergência (IVE) de plântulas de Anadenanthera colubrina

\begin{tabular}{lccccc}
\hline \multirow{2}{*}{ Substratos } & \multicolumn{4}{c}{ Profundidade $(\mathrm{cm})$} & Médias \\
\cline { 2 - 5 } & 0 & 1 & 3 & 5 & $3,8 \mathrm{a}$ \\
Composto & $5,7 \mathrm{Aa}$ & $4,5 \mathrm{Ba}$ & $4,0 \mathrm{Ba}$ & $0,9 \mathrm{Ca}$ & $2,0 \mathrm{~b}$ \\
Areia & $2,2 \mathrm{Bb}$ & $3,4 \mathrm{Ab}$ & $1,9 \mathrm{Bb}$ & $0,4 \mathrm{Ca}$ & $0,6 \mathrm{C}$ \\
\hline Médias & $4,0 \mathrm{~A}$ & $4,0 \mathrm{~A}$ & $3,0 \mathrm{~B}$ &
\end{tabular}

Médias seguidas pela mesma letra maiúscula na linha e minúscula na coluna não diferem significativamente entre si pelo teste de Tukey a $1 \%$ de probabilidade.

Este índice possui uma importância singular no que diz respeito ao estudo do desenvolvimento inicial de plântulas, visto que, há uma relação direta entre a velocidade na emergência e o crescimento das plântulas (SILVA et al., 2012). De acordo com Rodrigues et al. (2007), essa agilidade na emergência é uma estratégia da espécie para se 
estabelecer rapidamente no ambiente, usufruindo das condições ambientais favoráveis ao crescimento e desenvolvimento da plântula, sobretudo, no período chuvoso.

Silva et al. (2004), avaliando os efeitos do tipo do substrato e da profundidade de semeadura na emergência de angico-de-caroço [Anadenanthera macrocarpa (Benth.) Brenan], constataram que dentre os substratos testados (vermiculita, areia e solo), os maiores percentuais de emergência ocorreram em areia e vermiculita, na profundidade superficial, com 87\%; e em vermiculita a $2 \mathrm{~cm}$, com $85 \%$. Os menores valores ocorreram em solo, com $44 \%$, $7 \%$ e $16 \%$, respectivamente para 0,2 e $4 \mathrm{~cm}$. Segundo esses autores, o resultado mais promissor para IVE ocorreu em areia na profundidade superficial, com 18,87; seguida da vermiculita em 0 e $2 \mathrm{~cm}$, com 13,46 e 8,82, respectivamente. Os menores IVE's ocorreram no solo a 2 e $4 \mathrm{~cm}$, com 0,50 e 0,78 , respectivamente. Os autores verificaram ainda que não houve emergência a partir do $16^{\circ}$ dia após a semeadura e as sementes não germinadas ao término do experimento estavam mortas.

Para o tempo médio de emergência (TME), houve efeito significativo $(\mathrm{p} \leq 0.05)$ para a interação substrato $\times$ profundidade de semeadura (Tabela 5). Os maiores valores foram observados nas profundidades de 1 e $3 \mathrm{~cm}$ no substrato composto e 0 e $1 \mathrm{~cm}$ no substrato areia, respectivamente. Nestas profundidades, as sementes levaram cerca de 3 a 5 dias para emergir no substrato "composto" e em torno de 5 dias na areia. No entanto, na profundidade de $5 \mathrm{~cm}$, as sementes levaram em média 8 dias para emergir, independente do substrato avaliado. Esta é uma característica não desejável do ponto de vista da viveiricultura, visto que, plântulas que emergem mais vagarosamente podem se tornar mais susceptíveis as condições adversas do meio por passarem mais tempo nos estádios iniciais de desenvolvimento (MARTINS; NAKAGAWA; BOVI, 1999).

Tabela 5. Efeito da interação substrato $\times$ profundidade de semeadura sobre o tempo médio de emergência (TME) de plântulas de Anadenanthera colubrina

\begin{tabular}{|c|c|c|c|c|c|}
\hline \multirow{2}{*}{ Substratos } & \multicolumn{4}{|c|}{ Profundidade $(\mathrm{cm})$} & \multirow{2}{*}{ Médias } \\
\hline & 0 & 1 & 3 & 5 & \\
\hline Composto & $6,2 \mathrm{Ba}$ & $3,5 \mathrm{Cb}$ & $5,0 \mathrm{BCb}$ & $8,9 \mathrm{Aa}$ & $5,9 \mathrm{a}$ \\
\hline Areia & $5,2 \mathrm{Ba}$ & $5,4 \mathrm{Ba}$ & $8,1 \mathrm{Aa}$ & 8,3 Aa & $6,7 \mathrm{a}$ \\
\hline Médias & $5,7 \mathrm{BC}$ & $4,4 \mathrm{C}$ & $6,6 \mathrm{~B}$ & $8,6 \mathrm{~A}$ & \\
\hline $\mathrm{CV}=17,7 \%$ & & & & & \\
\hline
\end{tabular}

Médias seguidas pela mesma letra maiúscula na linha e minúscula na coluna não diferem significativamente entre si pelo teste de Tukey a $5 \%$ de probabilidade.

Na Tabela 6 são apresentados os valores médios do percentual de sobrevivência das plântulas de Anadenanthera colubrina em função da profundidade de semeadura. Observou-se que os maiores percentuais foram obtidos nas profundidades de 3 e $1 \mathrm{~cm}$, com 57 e $52 \%$, respectivamente. Enquanto que os menores valores ocorreram na profundidade superficial (rente ao substrato) e em $5 \mathrm{~cm}$, com 31 e $22 \%$, respectivamente.

Tabela 6. Efeito da profundidade de semeadura sobre o percentual de sobrevivência de plântulas de Anadenanthera colubrina

\begin{tabular}{ll}
\hline Profundidade $(\mathrm{cm})$ & Médias \\
\hline 0 & $31 \mathrm{~b}$ \\
1 & $52 \mathrm{a}$ \\
3 & $57 \mathrm{a}$ \\
5 & $22 \mathrm{c}$ \\
\hline $\mathrm{CV}=15,4 \%$ &
\end{tabular}

$\mathrm{CV}=15,4 \%$

Médias seguidas pela mesma letra na coluna não diferem significativamente entre si pelo teste de Tukey a $1 \%$ de probabilidade.

Oliveira et al. (2017) ao estudarem a dinâmica populacional da regeneração natural da Anadenanthera colubrina em fragmento florestal de Brejo de Altitude na Paraíba, constataram que o táxon apresentou uma mortalidade alta de $85,45 \%$ do total das parcelas estudadas na fase de plântula. De acordo com esses autores, diversos fatores bióticos e abióticos interferem no desenvolvimento de regenerantes no fragmento estudado, além da ação antrópica que apresenta alta interferência no desenvolvimento das plântulas. Além disso, a perpetuação dessa espécie no fragmento estudado depende, sobretudo, de condições apropriadas para germinação das sementes logo que dispersas e da presença das plantas jovens que ocorrem no sub-bosque da floresta.

A germinação de sementes e a sobrevivência das plântulas dependem intimamente de um conjunto de fatores ambientais. Dessa forma, o conjunto de condições necessárias para que se realize o processo de germinação e o estabelecimento da plântula pode ser favorecido, dentre outros fatores, pela profundidade de semeadura e pelo tipo de substrato, segundo suas capacidades para reter umidade em quantidade que possibilite a reidratação da semente; e para suprir o oxigênio necessário à atividade enzimática na fase germinativa (SILVA et al. 2004). 


\section{CONCLUSÕES}

O substrato "composto" favoreceu a emergência de plântulas e o vigor de sementes de Anadenanthera colubrina, em relação à areia.

As profundidades de semeadura de 1 e $3 \mathrm{~cm}$ são as mais indicadas para testes de emergência dessa espécie.

\section{REFERÊNCIAS}

ALVES, A. U.; CARDOSO, E. A.; ALIZANDRE, T. F.; CAVALCANTE, I. H. L.; BECKMAN-CAVALVANTE, M. Z. Emergência de plântulas de fava em função de posições e profundidades de semeadura. Biosci. J., Uberlândia, v.30, n.1, p.33-42, 2014.

ALVES, M. M.; ALVES, E. U.; BRUNO, R. L. A.; SILVA, K. R. G.; BARROZO, L. M.; SANTOS-MOURA, S. S.; CARDOSO, E. A. Germinação e vigor de sementes de Clitoria fairchildiana Howard (Fabaceae) em função da coloração do tegumento e temperaturas. Biosci. J., Uberlândia, v.29, n.1, p.216-223, 2013.

ARAÚJO, A. P.; SOBRINHO, S. P. Germinação e produção de mudas de tamboril (Enterolobium contortisiliquum (Vell.) Morong) em diferentes substratos, Revista Árvore, v.35, n.3, p.581-588, 2011.

CARVALHO, N. M.; NAKAGAWA, J. Sementes: ciência, tecnologia e produção. 5.ed. Jaboticabal: FUNEP, , 2012. $590 \mathrm{p}$.

DUTRA, T. R.; MASSAD, M. D.; SARMENTO, M. F. Q.; OLIVEIRA, J. C. Emergência e crescimento inicial da canafístula em diferentes substratos e métodos de superação de dormência. Revista Caatinga, Mossoró, v. 25, n. 2, p. 65-71, 2012.

IBGE, Instituto Brasileiro de Geografia e Estatística. Estados. 2012. Acessado em 05 de Julho de 2019. Disponível em: http://www.ibge.gov.br.

LORENZI, H. Árvores brasileiras: manual de identificação e cultivo de plantas arbóreas do Brasil. 4.ed Nova Odessa: Instituto Plantarum, 2002. p. 188.

MARTINS, C. C.; NAKAGAWA, J.; BOVI, M. L. Efeito da posição da semente no substrato e no crescimento inicial das plântulas de palmito-vermelho (Euterpe espiritosantensis Fernades - Palmae). Revista Brasileira de Sementes, Brasília, v.21, n.1, p.164-173, 1999.

MOREIRA, F.M.; NÓBREGA, R.S.A.; SANTOS, R.P.; SILVA, C.C.; NÓBREGA J.C.A. CULTIVATION OF Caesalpinia pulcherrima L. Sw. IN REGIONAL SUBSTRATES. Rev. Árvore, Viçosa, v.42, n.2, 2018. doi: dx.doi.org/10.1590/1806-90882018000200012.

MORIM, M.P. Anadenanthera in Flora do Brasil 2020 em construção. Jardim Botânico do Rio de Janeiro. Disponível em: <http://floradobrasil.jbrj.gov.br/reflora/floradobrasil/FB18071>. Acesso em: 10 Ago. 2019.

OLIVEIRA, F. G.; JARDIM, M. A. G. Emergência de Acacia farnesiana (1.) Willd. (Fabaceae) e Pouteria ramiflora Radlk. (Sapotaceae) em diferentes substratos. Revista da Sociedade Brasileira de Arborização Urbana, v. 8, n. 4, p. $1-7,2019$.

OLIVEIRA, I. S. S.; SOUZA, V. C.; MEDEIROS, R. L. S.; BARBOSA NETO, M. V.; BARBOSA, A. S.; AZEREDO, G. A. Regeneração Natural de Anadenanthera colubrina (Vell.) Brenan Fabaceae em Brejo de Altitude em Bananeiras, Paraíba. Revista Verde de Agroecologia e Desenvolvimento Sustentável, v.12, n.4, p.680-686, 2017.

RODRIGUES, A. C. D. C.; OSUNA, J. T. A.; QUEIROZ, S. R. D. O.; RIOS, A. P. S. Effect of subsrate and luminosity on the germination of Anadenanthera colubrina (Fabaceae, Mimosoideae). Revista Árvore, v. 31, n. 2, p. 187-193, 2007.

SANTOS, Á. S. Época de semeadura e substrato na produção de mudas de Caesalpinia pulcherrima (L.) Sw. $21 \mathrm{f}$. Dissertação (Mestrado em Agronomia - Produção Vegetal). Universidade Estadual Paulista (Unesp), Faculdade de Ciências Agrárias e Veterinárias, Jaboticabal/SP. 2019.

SENA, F. H.; LUSTOSA, B. M.; ALMEIDA-CORTEZ, J. S. Ecofisiologia da germinação de sementes de Anadenanthera colubrina (Vell.) Brenan (Fabaceae). Gaia Scientia, v.11, n4, p.1-8, 2017. 
SILVA, J. H. C. S. et al. Emergência de plântulas e vigor de sementes de Anadenanthera colubrina (Vell.) Brenan (Fabaceae) em diferentes substratos e profundidades de semeadura. In: II Congresso Paraibano de Agroecologia \& IV Exposição Tecnológica, 2019. Anais... Caderno Verde de Agroecologia e Desenvolvimento Sustentável, Pombal, v. 9, n.7, e-7054, 2019.

SILVA, A. C. F.; SILVEIRA, L. P.; NUNES, I. G.; SOUTO, J. S. Superação de dormência de Enterolobium contortisiliquum Mor.(Vell.) Morong. Scientia Plena, v. 8, n. 4 (b), 2012.

SILVA, A.; FIGLIOLIA, M. B.; AGUIAR, I. B. Germinação de sementes de Acacia polyphylla DC. (monjoleiro) e de Aspidosperma ramiflorum müll. arg. (guatambu). Floresta, Curitiba, v. 37, n. 3, 2007.

SILVA, C. S. B.; BARBOSA, F.; MACHADO, J. D. C.; KIILL, L.;MAGALHÃES, E. E.; SOUZA, E. A. Influência do substrato e da profundidade de semeadura na germinação de sementes de angico-de-caroço [Anadenanthera macrocarpa (Benth.) Brenan-Leguminosae]. In: Embrapa Semiárido-Artigo em anais de congresso (ALICE). In: Reunião Nordestina de Botânica, 27., 2004, Petrolina, PE. [Anais...]. Petrolina: SBB; Embrapa Semi-Árido; UNEB, 2004. 1 CD-ROM. Resumo., 2004.

SILVA, R. P. D.; CORÁ, J. E.; CARVALHO FILHO, A.; FURLANI, C. E. A.; LOPES, A. Efeito da profundidade de semeadura e de rodas compactadoras submetidas a cargas verticais na temperatura e no teor de água do solo durante a germinação de sementes de milho. Ciência e Agrotecnologia, Lavras, v.32, n.3, p.929-937, 2008.

\section{AGRADECIMENTOS}

Apoio financeiro: Fundação de Apoio à Pesquisa do Estado da Paraíba - FAPESQ. 